Hershkovitz - Cistanthe

\title{
On the taxonomic identities of the names Calandrinia speciosa Lehm. and Calandrinia spectabilis Otto \& Dietr. (Montiaceae)
}

\author{
Mark A. Hershkovitz \\ Santiago, Chile \\ cistanthe@gmail.com
}

\begin{abstract}
Calandrinia speciosa Lehm. and Calandrinia spectabilis Otto \& Dietr. are 1830s-vintage validlypublished names of Chilean plant species evidently pertaining to taxa currently classified in Cistanthe sect. Cistanthe (Montiaceae). The taxonomic status of both names is problematic, because they were not typified or illustrated, their precise Chilean provenance is unknown, and their diagnoses/descriptions might apply to more than one species. Both names have been and continue to be applied taxonomically haphazardly. The existence of two later conceptually heterotypic synonyms of $C$. speciosa Lehm, viz. $C$. speciosa Lindl. non Lehm. and C. speciosa Hook. non Lehm., has exacerbated the confusion. The present work summarizes the history of the application of these names in botanical taxonomy and horticulture. Both likely, but not unequivocally, refer to plants of the later-described, typified, and otherwise welldocumented species Calandrinia laxiflora Phil. [三 Cistanthe laxiflora (Phil.) Peralta \& D.I. Ford]. But persistent ambiguities justify proposals to reject both $C$. speciosa and $C$. spectabilis.

KEY WORDS: Calandrinia, Cistanthe, Montiaceae, taxonomy, nomenclature.
\end{abstract}

\section{Introduction}

Calandrinia speciosa Lehm. (Lehmann, 1831) and Calandrinia spectabilis Otto \& Dietr. (1833) are validly published names of presumptive plant species from Chile. From their diagnoses, descriptions, and historical application, both appear to pertain to the monophyletic genus Cistanthe Spach, in particular, the monophyletic Cistanthe sect. Cistanthe (Hershkovitz, 2019). However, their precise taxonomic identification cannot be ascertained on the basis of available evidence. Both species were described on the basis of plants cultivated from seeds from secondary sources in Europe lacking precise Chilean provenance. Neither name was typified, and neither plant was illustrated.

The original diagnoses/descriptions of both species are applicable to more than one Chilean species. The taxonomic application of their names historically has been inconsistent, contradictory, and fundamentally baseless. The identity of Calandrinia speciosa Lehm. is further confused, because three species were described by this name: $C$. speciosa Lehm., C. speciosa Lindl. non Lehm., and C. speciosa Hook. non Lehm. For clarity, throughout this work, the corresponding authority of these homonyms, but not other taxa, will be reiterated. Current comprehensive catalogs of the regional flora (Peralta and FordWerntz, 2008; Rodríguez et al., 2018) consider both names to be synonyms of Cistanthe grandiflora (Lindl.) Schltdl. Ironically, this particular taxonomic identity can be ruled out.

The purpose of the present paper is to clarify as best as possible the taxonomic identities of the names $C$. speciosa Lehm. and C. spectabilis. Emphasis will be on taxonomic evidence especially from $19^{\text {th }}$ and early $20^{\text {th }}$ century references, on which the modern taxonomy is based. This evidence will be compared with modern usage. The conclusion that emerges is that both names most likely refer to plants currently classified under the later name Calandrinia laxiflora Phil. [三Cistanthe laxiflora (Phil.) Peralta \& D.I. Ford]. Furthermore, both names might be based on plants propagated from the same original but undocumented Chilean collection. However, the evidence is not unequivocal, hence the question of identity remain unresolved. 
Hershkovitz - Cistanthe

\section{Materials and methods}

Historical and current taxonomic/floristic literature and taxonomic and herbarium databases were reviewed. In addition, internet document and image searchers were performed for the search terms Calandrinia speciosa and Calandrinia spectabilis. Information related to the identities of these names was synthesized into a narrative summarizing historical and current taxonomic usage.

\section{Results}

At the outset, I emphasize that throughout the $20^{\text {th }}$ century, plants of all Chilean species (one crossing the border into Argentina) of Cistanthe sect. Cistanthe most commonly were classified as Calandrinia grandiflora Lindl. or its homotypic synonym Cistanthe grandiflora (Phil.) Schltdl. (Hershkovitz, 2018a; cf. Muñoz Pizarro, 1966; Hershkovitz, 1991, Hofmann 1998). This was consequent to Reiche's (1898) taxonomic treatment of the section, which lumped the then-published segregates recognized by Barnéoud (1846) and Philippi (1893). Reiche's (1898) posture is understandable for reasons outlined in Hershkovitz (2018a). Nevertheless, it is untenable, as, in vivo, about 10 species are distinguishable based on morphology, geography, and ecology (Hershkovitz, 2018a; cf. Muñoz Pizarro, 1966; see also discussion below). The consequence is that, during the $20^{\text {th }}$ century, the taxonomic identities of $C$. speciosa Lehm. and $C$. spectabilis were not so problematic, because synonymy with $C$. grandiflora was presumed. The problem reemerged in the context of the current taxonomy.

\section{Taxonomy of C. speciosa Lehm.}

Based on the protolog and circumstantial evidence, C. speciosa Lehm. conceivably could refer to any of four species: Cistanthe discolor (Schrad.) Spach [= Calandrinia discolor Schrad.], Cistanthe laxiflora, Cistanthe philhershkovitziana Hershk., and Cistanthe mucronulata (Meyen) Carolin ex Hershk. [= Calandrinia mucronulata Meyen]. It was described in a commercial seed list from a plant "ex horto Parisiensi" (Lehmann, 1831). Chilean origin was not specified and here is presumed. Lehmann's protolog was republished verbatim subsequently by Schlectendal (1831). Index Kewensis currently lists the authority of Calandrinia speciosa as Lehm. ex Schlect. (International Plant Names Index, 2011), but Lehmann's publication appears to be valid. There appears to be no type specimen, and no illustration corresponds to the described plant.

The protolog of $C$. speciosa Lehm. indicates that the plant had terete stems, which explicitly served to discriminate it from Cistanthe grandiflora, which has prominently angled stems. But terete (or subterete) stems also characterize the previously published Cistanthe discolor, as well as C. laxiflora, C. mucronulata, and C. philhershkovitziana. Lehmann's protolog also specifies that the stem is "subaphyllis," which characterizes all of these species except $C$. laxiflora, which has leafy stems as long as $3 \mathrm{~m}$. However, the inflorescence culm of $C$. laxiflora is not leafy. Younger and cultivated plants may appear more rosettiform, such that the term "stem" might refer only to the long, leafless inflorescence (see below).

Identification of $C$. speciosa Lehm. took a turn with Otto and Dietrich's (1833) publication of Calandrinia spectabilis in a horticultural journal. Here, Otto and Dietrich listed C. speciosa as a synonym of Calandrinia discolor. Calandrinia spectabilis was distinguished from $C$. discolor on the basis of the conspicuously red abaxial leaf surface of the latter, and from $C$. grandiflora by the stem geometry trait. But Lehmann's (1831) protolog does not refer to leaf color. 
Hershkovitz - Cistanthe

Another turn of events was the publication and illustration of Calandrinia speciosa Hook. non Lehm. (Hooker, 1835). This plant was cultivated from seed obtained from a Scottish source. From the illustration, the plant can be diagnosed taxonomically as Cistanthe laxiflora, especially because of the soillustrated thick green stem with unelongated internodes bearing leaf scars. Hooker described the stems as similar to Sempervivum arboreum L [= Aeonium arboreum (L.) Webb \& Berthel]. As this is exactly the diagnostic form of (and only) C. laxiflora, the identity of $C$. speciosa Hook. non Lehm. cannot be in doubt. Hooker (1835) thus provided the first documentation of $C$. laxiflora in Europe. My scanning of herbarium databases revealed no earlier specimens.

Hooker (1835) indicated that the specimen as received bore the epithet "speciosa," and he concluded erroneously that the name had not been applied previously in Calandrinia. It had been applied, not once, but twice (see below). But this demonstrates that Hooker was not referring to Lehmann's plant, which is not always clear for homonyms published pre-Code. This is unfortunate, because, had Hooker chosen a unique name, an argument could be made for its conservation against $C$. laxiflora. Because Hooker's name is illegitimate, and there is no doubt as to its identity, I have not sought to locate and verify a type. The fact that the cultivated specimen as received bore the epithet "speciosa" circumstantially suggests (but does not prove) that it is the same as Lehmann's plant, hence that the latter also is C. laxiflora. But it is not unusual in "popular" horticultural taxonomy to apply the same species name to similar but taxonomically distinct plants.

Spach (1836) considered $C$. speciosa Hook. non Lehm. as a variety of $C$. discolor differing in having stems unbranched and leaf surfaces green/glaucous throughout. Internet images demonstrate that such "albino" forms of $C$. discolor exist in the coast ranges of Chile's Coquimbo Region, but I defer documentation for a future work on the genus. Spach (1836) made no reference to C. speciosa Lehm. Steudel (1840), in contrast, listed $C$. speciosa Lehm. as a synonym of $C$. discolor but made no reference to $C$. speciosa Hook. non Lehm. Thus, already there had emerged evidence of confusion.

Lilja (1841) followed Spach (1836) in recognizing Cistanthe as distinct from Calandrinia. He recognized "C[istanthe] speciosa (Lilja, msc.)" (see below) as having the synonym(s?), "C[istanthe] grandiflora Hort. an Lindl. vel C [istanthe] spectabilis Otto et Dtr." Since Spach (1836) is cited and Lehmann (1831) is not, presumably Lilja (1841) reference is to C. speciosa Hook. not Lehm. Still, Lilja's diagnostic thus is ambiguous, as it is not clear it he refers to one or the other or both. Either way, it is problematic, because Otto and Dietrich (1833) clearly distinguished C. grandiflora and C. spectabilis.

Although Lilja's (1841) work based on Spach (1836), he made no reference to Spach's inclusion of $C$. speciosa Hook. non Lehm. in C. discolor. Likewise, he made nor reference to Steudel's synonymy of $C$. speciosa Lehm. with C. discolor. Lilja (1841) reservedly recognized Cistanthe glauca (Schrad) Spach [= Calandrinia glauca Schrad], suggesting it was a variety of " $C$. speciosa (Lilja msc.)." But $C$. glauca is a synonym of $C$. grandiflora, having the same morphology, the types indistinguishable, and the type localities essentially the same (Veldkamp, 2015; Hershkovitz, 2018a). Thus, notwithstanding the ambiguity in his synonymy of " $C$. speciosa Lilja, msc.)," Lilja (1846) effectively did consider $C$. grandiflora (as $C$. glauca) as a possible synonym of $C$. speciosa Hook. non Lehm.

A nuance is that, evidently erroneously, Lilja's (1841) "C. speciosa (Lilja, msc.)" referenced not C. speciosa Lehm. or C. speciosa Hook. non Lehm., but Calandrinia speciosa Lindl. (Lindley, 1833), a third species of Calandrinia published with this epithet. Calandrinia speciosa Lindl. non Lehm. was renamed by Spach (1836) as C. elegans Spach. It is a taxonomic synonym of Calandrinia menziesii (Hook.) Torrey \& A. Gray (Hershkovitz, 2018a; 2019). Lilja's (1841) description of Cistanthe ("semina...pubescentia," "bracteis calycibusque nigro-punctatis") clearly refers to plants of Cistanthe and 
Hershkovitz - Cistanthe

not Calandrinia. Peralta and Ford-Werntz (2008), Hershkovitz (2018a), and Rodríguez et al. (2018) cited the name "Cistanthe speciosa (Lehm.) Lilja," but this combination does not exist.

Barnéoud (1846) recognized $C$. speciosa Lehm. as a distinct species with no synonyms. He republished Lehmann's (1831) protolog, but cited Hooker's (1835) illustration of the heterotypic $C$. speciosa Hook. non Lehm. He described C. speciosa Lehm. as a "precious plant" with leaves disposed in a "species" of rosette subtending unbranched naked stems with very large flowers. The error aside, Barnéoud's (1846) description confirms that the "stems" in descriptions of C. laxiflora can refer to the leafless inflorescence and not the vegetative stem system. In any case, Barnéoud's (1846) notion of $C$. speciosa Lehm. evidently pertains to $C$. speciosa Hook. non Lehm., hence C. laxiflora.

Philippi (1893) emphasized his frustration in attempting to classify species of Cistanthe sect. Cistanthe, which he classified as Calandrinia sect. Grandiflorae Philippi." He noted that Barnéoud (1846) merely had copied Lehmann's (1831) protolog of C. speciosa Lehm., and he doubted that Barnéoud ever had seen a specimen or even the cited Hooker (1835) illustration of $C$. speciosa Hook. non Lehm. Like Barnéoud, Philippi (1893) evidently did not notice that Lehmann's (1831) and Hooker's (1835) species were heterotypic homonyms. In fact, Barnéoud's (1846) prosaic description of C. speciosa Lehm. fits Hooker's description and illustration well. Moreover, since Barnéoud worked in Paris, the source of Lehmann's plant, it is not unreasonable to suspect that he had seen a cultivated individual identified as C. speciosa [Hort.], and this might well have been $C$. laxiflora.

But with no diagnostic justification, Philippi (1893) reservedly referred to C. speciosa Lehm. a plant from Constitución (CHILE. Maule Region. Talca Province). He noted that he himself had not seen Hooker's (1835) illustration, rendering perplexing both his criticism of Barnéoud and his baseless identification of the Constitución plant. Based on locality and description, Philippi's (1893) plant almost certainly is Cistanthe mucronulata (see Hershkovitz, 2018a).

Reiche (1898) seemed to share Philippi's frustration with Cistanthe taxonomy. But, whereas Philippi (1893) insisted that variants in this group were distinct species, Reiche (1898; but see below) lumped all in synonymy with Calandrinia grandiflora. Philippi's (1893) observations and opinions seem to have been ignored, possibly because Philippi tended towards excessive species splitting. For example, of 80 the Chilean species of Calandrinia s.l. (Hershkovitz, 2018a, 2019) described by Philippi (1893), Reiche accepted only 26, while rejecting 42 and listing the remaining 12 as subspecific taxa. Similarly, in her thorough revision of Montiopsis subg. Montiopsis (Montiaceae), radically modified from Reiche (1898), Ford[-Werntz] (1992) rejected more than half of Philippi's species. But, notwithstanding notable errors, Philippi's (1893) treatment of Cistanthe sect. Cistanthe is more accurate than that of Reiche (1898).

Reiche's (1898) broader circumscription of $C$. grandiflora pervaded throughout the following century (Hershkovitz, 2018a; cf. Muñoz Pizarro, 1966). Hershkovitz (2018a) explained this as a consequence of poor diagnostic value and/or preservation of herbarium specimens. But it also reflects lack of a subsequent comprehensive revision of the genus or even its Chilean species. To get a historical perspective, the first published "revision" of Reiche's (1898) treatment - five years before Wilbur Wright's first flight at Kitty Hawk - is the admittedly rudimentary and crude treatment of Hershkovitz (2018a) - fifty years after astronauts orbited the moon. Western civilization is idiosyncratic. Meanwhile, in the intervening period, inconsistent/contradictory lists of various Cistanthe species, lacking diagnostics or references thereto, have been included in ad infinitum catalogs of Chilean vascular plants at various geographic scales, including Marticorena and Quezada (1985), Peralta (1993), Marticorena et al. (2001), Peralta and Ford-Werntz (2008), Squeo et al. (2008), Rodríguez et al. (2018), RBGE (2019), and at least a score more at more localized scales. 
Hershkovitz - Cistanthe

However, Reiche (1898) diagnosed informally three forms of $C$. grandiflora. His C. speciosa Lehm. form was distinguished from his $C$. grandiflora s.str. form on the basis of leaf shape, and both of these from his $C$. discolor form on the basis of the aforementioned leaf coloration. He made no mention of the diagnostic stem trait emphasized by Lehmann (1831) and Otto and Dietrich (1833). Perhaps consequently, he referred the terete-stemmed $C$. laxiflora to the angled-stemmed $C$. grandiflora s.str. form. Most peculiarly, Reiche (1898) listed Calandrinia bracteosa Phil. as a synonym of his C. speciosa form. Although Philippi (1893) classified this species in his Grandiflora group, based on the description and the type locality (CHILE. Nuble Region. Diguillín Province.: Chillán), C. bracteosa can be identified as a plant closely related to Cistanthe arenaria (Cham.) Carolin ex Hershk. (Cistanthe sect. Rosulatae (Reiche) Hershk.; Hershkovitz, 2018a, 2019). Reiche (1898) provided no distributional data for the three forms of C. grandiflora (but see below).

Reiche's subsequent account of Chilean plant geography (1907) suggests that he considered at least some plants of Cistanthe laxiflora to pertain to "Calandrinia speciosa." For clarity, I cite here "Reiche, 1907; 2007," the latter an edited reprinting of G. Looser's 1934 translation of Reiche (1907). Reiche $(1907$; 2007: 255) referred to plants growing on coastal rocks in the vicinity of the mouth of the Río Limarí (CHILE. Coquimbo Region. Limarí and Elqui Provinces) as Calandrinia speciosa (without authority). Depending on the exact location, these plants might be Cistanthe aegitalis (F. Phil.) Carolin ex Hershk. or Cistanthe laxiflora (Hershkovitz, 2018a). But anywhere in this vicinity, they also could be the ubiquitous "true" C. grandiflora (Hershkovitz, 2018a).

At the coast at Los Vilos (CHILE: Coquimbo Region. Choapa Province), Reiche (1907; 2007: 260) erroneously referred to plants with fleshy, woody stems and red-stained leaves as Calandrinia discolor. With no doubt, these plants are Cistanthe laxiflora. The leaves may turn reddish throughout with age and/or under water stress [see photos in RBGE (2019)], but this does not resemble the leaf surface color dimorphism of $C$. discolor [illustrated in Muñoz Pizarro (1966); see URL in Literature Cited]. Moreover, C. discolor is a cordilleran (never coastal) species of Chile's Metropolitan, Valparaiso, and Coquimbo regions (Hershkovitz 2018a; contra Philippi, 1860).

Finally, Reiche (1907; 2007: 266) referred to fleshy-stemmed coastal plants in between Los Vilos and Zapallar (CHILE. Valparaiso Region. Petorca Province) as a form pertaining to C. speciosa (without author). These plants are either C. laxiflora or C. grandiflora s.str. Both are common in this zone. Their niches are different, but they abut, such that the two species may be found growing virtually side-by-side. But their morphological distinctions are striking (Hershkovitz, 2018a), so it is difficult to understand how Reiche could have overlooked them. However, C. grandiflora shoots are vernal and die back with the ensuing summer drought, whereas $C$. laxiflora persists. Thus, if only one species was observed, I am inclined to believe that it was C. laxiflora. If this speculation is correct, it demonstrates that Reiche (1907; 2007) may have referred to plants of $C$. laxiflora as $C$. speciosa (without author). If Reiche's (1898) concept of $C$. speciosa Lehm. actually based on $C$. speciosa Hook. non Lehm., this would not be surprising.

The preceding discussion demonstrates that the name Calandrinia speciosa Lehm. has been applied to Cistanthe grandiflora s.str. and multiple segregates, in particular, Cistanthe discolor, $C$. laxiflora, C. mucronulata, and possibly also C. aegitalis. In addition, the protolog also fits $C$. philhershkovitziana (Hershkovitz, 2018b). But Lehmann's (1831) protolog establishes only that $C$. speciosa is distinct from Cistanthe grandiflora,

It is unlikely that material of $C$. aegitalis reached Europe by 1831 , so this identity of $C$. speciosa Lehm. can be ruled out. Meyen's collection of C. mucronulata would not have arrived until 1832 (cf. Meyen, 1934). But, earlier, Bertero might have collected this species near Rancagua [CHILE. O'Higgins Region. Cachapoal Province.] (cf. Delprete et al., 2002). I have not located such a Bertero specimen, but 
Hershkovitz - Cistanthe

the fate of some of his collections remains unknown (Delprete et al., 202). Bertero's 1829 collection of $C$. philhershkovitziana is documented (Hershkovitz, 2018c). While I doubt that $C$. speciosa Lehm. is an "albino" C. discolor (Spach, 1836), it is not impossible.

At the same time, it must be reemphasized that the earliest documentation of the presence of $C$. laxiflora in Europe is Hooker's (1835) illustration. This is somewhat surprising, because, on coastal cliffs and beach rock outcrops immediately north and south of Valparaiso, C. laxiflora is common and, from afar, conspicuous. It is difficult to believe that early European botanists docking in Valparaiso and exploring nearby beaches would have overlooked it, unless they were pretty liquored up.

After Reiche (1898), references to C. speciosa Lehm. are rare, likely because it was considered an incognito synonym of $C$. grandiflora. Also, notably, $C$. speciosa Hook. non Lehm. seems to have been orphaned. The only explicit citation was in Spach (1836). It was not referenced by Steudel (1840). Authorship of Lilja's (1841) C. speciosa was not specified. Barnéoud (1846) and Philippi (1893) seemed to believe both names referred to $C$. speciosa Lehm. Reiche (1898) referred only to C. speciosa Lehm. Reiche $(1907,2007)$ did not specify the authorship of $C$. speciosa, but the editors of Reiche (2007) presumed it to be $C$. speciosa Lehm., and they reservedly considered this to be a synonym of Cistanthe grandiflora. As noted above, Reiche's notion of $C$. speciosa Lehm. probably pertained to C. speciosa Hook. non Lehm.

Marticorena and Quezada's (1985) catalog of the Chilean flora included (without synonymy) five species corresponding to Cistanthe sect. Cistanthe, C. speciosa Lehm. not among these. But Marticorena and Quezada's (1985) list of accepted species does not seem to follow any taxonomic rhyme or reason relative to previously published works, and, lacking synonymy, it has little taxonomic diagnostic value. Peralta's (1993) accounting of Cistanthe species does not include or mention C. speciosa. This work identified localities of some Cistanthe species, but did not elaborate on taxonomic diagnostics.

Muñoz Schick (1985) described and illustrated a plant from the Copiapó area as C. speciosa Lehm. The basis for this identification was not stated. But, as evident from the photo and description of its leafy stems, it does not conform to Lehmann's (1831) protolog or, for that matter, Hooker's (1833) description and illustration of $C$. speciosa Hook. non Lehm. Hershkovitz (2006) used Muñoz Schick's (1985) photos and description to (mis)identify a similar Cistanthe collected near Copiapó. Possibly based on Muñoz Schick (1985), but without citing a specific reference, Squeo et al. (2008) included C. speciosa Lehm. in their list of Atacama Region plants, indicating its range as Copiapó and Tierra Amarilla Provinces. They also indicated that the species might be "vulnerable." Certainly it has been vulnerable to taxonomic confusion, since its identity never has been established. The comprehensive catalogs of Peralta and Ford-Werntz (2008) and Rodríguez et al. (2018) list C. speciosa as a synonym of Cistanthe grandiflora.

\section{Taxonomy of $C$. spectabilis Otto \& Dietr.}

The other problematic taxon is Calandrinia spectabilis, which was described in a horticultural journal as a fruticose and subterete-stemmed species originally from Chile (Otto and Dietrich, 1833). Again, there is no type specimen, no precise Chilean locality, and no illustration. Its source was a private collector in, again, Paris. However, the original collector was identified as Carlo Bertero. Otto and Dietrich (1833) noted that the name associated with Bertero's collection was "Talinum crassifolium." But evidently Bertero applied this adjective to more than one Cistanthe collection, including a specimen of $C$. philhershkovitziana Hershk. (Hershkovitz, 2018c). 
Hershkovitz - Cistanthe

Per Bertero's itinerary (Delprete et al., 2002), he might have collected any or all of three other Cistanthe sect. Cistanthe species besides C. philhershkovitziana: C. laxiflora, C. grandiflora, and $C$. mucronulata. As Delprete et al. (2002) noted, Bertero published serially in a Santiago newspaper an informal list of his collections, ordered alphabetically by genus. But the final list terminated with the "P's," so his so-classified Talinum collections never were published.

The diagnosis/description of $C$. spectabilis (viz., fruticose and subterete-stemmed) precludes identity with $C$. grandiflora and $C$. philhershkovitziana, and are more consistent with $C$. laxiflora than $C$. mucronulata. In particular, the leaves are described as lanceolate-rhombic, whereas those of $C$. mucronulata are more broadly obovate (Philippi, 1893; Hershkovitz, 2018a) However, leaves of $C$. laxiflora, especially in cultivation, also can be more broadly obovate, although generally they are narrower in aspect than those of C. mucronulata (pers. obs.).

As noted above, $C$. spectabilis had been regarded as distinct (i.e., by Otto and Dietrich, 1833) and as a possible synonym of "C. speciosa (Lilja, msc.)" (Lilja, 1841). The latter likely refers to C. speciosa Hook. non Lehm, hence to C. laxiflora (see above). Its antecedents (viz., elaborate diagnosis/description in an [albeit obscure] journal and identification of its origin from a Bertero collection obtained from a named Parisian dealer) would seem to impart the species with a greater degree of plausibility than $C$. speciosa. The latter, as noted, merely was diagnosed briefly in a footnote of a long commercial seed list. Yet, in the taxonomic/floristic literature, compared to C. speciosa Lehm., C. spectabilis has received little attention. But similar to $C$. speciosa Lehm., its status has been questioned, its usage has been inconsistent and contradictory, its diagnosis is ambiguous, and, of course, its documentation is inadequate.

Barnéoud (1846) recognized C. spectabilis as distinct, but simply repeated Otto and Dietrich's (1833) diagnostic and indicated its occurrence Chile. Philippi (1893) questioned the status of $C$. spectabilis, asserting again that Barnéoud had not seen a specimen. But, again, having so-criticized Barnéoud (see above), Philippi, himself having seen neither the specimen, nor the publication, proposed that $C$. spectabilis corresponded to a plant from Talcahuano (CHILE. Bíobío Region. Concepción Province) whose characteristics, as he noted, contradicted those of the protolog/description in Barnéoud (1846), copied from Otto and Dietrich (1833). Philippi (1893) failed to note that his description of the plant he believed to be $C$. spectabilis was essentially the same as that of Cistanthe arenaria (Cham.) Carolin ex Hershk. from essentially the same locality (Chamisso, 1831), and it probably is that species (Hershkovitz, 2018a).

Reiche (1898) apparently ignored Philippi’s (1893) account and, without commentary, listed $C$. spectabilis as a synonym of his $C$. grandiflora s.str. form, i.e., excluding $C$. discolor and $C$. speciosa Lehm. (possibly referring to $C$. speciosa Hook. non Lehm.; see above) and the synonyms he associated with these. Peralta and Ford-Werntz (2008) and Rodríguez et al. (2018), while accepting Cistanthe laxiflora, also listed $C$. spectabilis as a synonym of $C$. grandiflora. Synonymy with $C$. grandiflora in the sense of Hershkovitz (2018a) is untenable given Otto and Dietrich's (1833) diagnosis.

But, while $C$. spectabilis has been given little credence in the taxonomic/floristic literature, it became widely applied in the horticultural realm. An internet search revealed that, after Calandrinia/Cistanthe grandiflora, $C$. spectabilis is the most commonly applied name for $C$. laxiflora. Some commercial/informational sites indicate explicitly that Cistanthe grandiflora is the current name for C. spectabilis. This suggests that use of the name $C$. spectabilis may have been more common previously.

The use of $C$. spectabilis in horticulture provides a clue as to its identity. The ambiguity and scarcity of the name in botanical application seems to render unlikely that the horticultural application is consequent to consultation of the taxonomic/floristic literature. Its frequent horticultural application, therefore, may represent vestigial but continuous usage following Otto and Dietrich's (1833) original 
Hershkovitz - Cistanthe

publication. This is circumstantial evidence, though not scientific proof, that $C$. spectabilis refers to $C$. laxiflora.

A breakthrough in the case would be the discovery of the Bertero collection on which $C$. spectabilis was based. Inquiries to G, P, and TO and searches of other databases revealed no such specimen. Circumstantial evidence suggests that the Bertero specimen is the origin also of $C$. speciosa Lehm. and C. speciosa Hook. non Lehm. In particular, the source of both C. speciosa Lehm. and $C$. spectabilis is Paris, evidently a destination for much of Bertero's haul (Delprete et al., 2002). And the Scottish source plant of $C$. speciosa Hook. non Lehm. already was thusly named. This suggests that the Scottish source either inferred that the plant was the same as Lehmann's, or that it actually was derived from the same source. Again, the evidence is not unequivocal.

\section{Conclusions}

The evidence suggests but does not prove that both Calandrinia speciosa Lehm. and $C$. spectabilis Otto \& Dietr. most likely are taxonomically the same as the later described Cistanthe laxiflora (Phil.) Peralta \& D.I. Ford. A serious caveat is that this conclusion was reached purely intuitively. Its validity must be corroborated by Bayesian model-based statistical nomenclatural analysis. Corroboration of the result will create the dilemma of having to decide which name should have priority for this species. Each name has its merits and demerits.

Alternative 1: conservation of C. speciosa Lehm. The principal justification for prioritization of C. speciosa Lehm. is its technical priority, assuming that it is indeed C. laxiflora. But its identity and provenance are the least well documented among the three names. Evidence of its identity as $C$. laxiflora is discombobulated, derived from clues gleaned from the publications of $C$. spectabilis and $C$. speciosa Hook. non Lehm. Moreover, historical application of the name has been the most inconsistent, contradictory, and erroneous, and evidently it has been confused with its later homonym. Only Reiche (1907; 2007) possibly referred plant of $C$. laxiflora to C. speciosa Lehm., and, even then, Reiche's concept of $C$. speciosa Lehm. might have referred subliminally to $C$. speciosa Hook. non Lehm. Peralta and Ford-Werntz (2008) and Rodríguez et al. (2018), incidentally, did not list $C$. speciosa Hook. non Lehm., which also might reflect the legacy of confusion.

Conservation of $C$. speciosa Lehm. against $C$. laxiflora implicates demonstration that a plausible type is unrecoverable, neotypfication, and perhaps formal conservation of the neotype against an eventually emergent type candidate, especially if this proves to be a species other than C. laxiflora. Alternatively, investigation might locate and identify the Bertero specimen associated with C. spectabilis, determine its conspecificity with $C$. laxiflora, and, as discussed above, proof might emerge that this also is the source of $C$. speciosa Lehm. Good luck.

Alternative 2: conservation of $\boldsymbol{C}$. spectabilis: The argument for conserving C. spectabilis is, on the balance, not much better. In its favor, the name has been widely used in horticulture. But horticultural taxonomy must follow botanical, hence the weight of this factor is little. Description of C. spectabilis is more detailed than that of $C$. speciosa Lehm., and there remains a possibility that the corresponding Bertero source might emerge. The principal evidence of its identity is the plausibility that historical conservation of the horticultural name documents its identity as $C$. laxiflora. But, as with $C$. speciosa, application of the name $C$. spectabilis in taxonomy/floristics has been inconsistent and erroneous. Evidence of its application to plants of $C$. laxiflora is indirect, involving possible but not certain historical identification of plants of C. laxiflora as plants of $C$. speciosa Lehm. or "Lilja, msc." that, in fact, possibly are C. speciosa Hook. non Lehm., which is C. laxiflora. ¿Huh? 
Hershkovitz - Cistanthe

Likewise, as with $C$. speciosa Lehm., conservation of $C$. spectabilis implicates demonstration that a plausible type is unrecoverable, neotypfication, and perhaps formal conservation of the neotype against an eventually emergent type candidate, especially if this proves to be a species other than $C$. laxiflora. Alternatively, investigation might locate and identify the Bertero specimen associated with $C$. spectabilis and determine its conspecificity with $C$. laxiflora.

Alternative 3: conservation of C. laxiflora: The argument for conservation of Cistanthe laxiflora against the other two names rests in its current typification, its precise provenance, verified taxonomic identity and diagnostics, and description of its distribution (Hershkovitz, 2018a). There are no encumbrances against its conservation.

Remarkably, however, the name $C$. laxiflora has been perhaps the least applied historically, both taxonomically/floristically and popularly. Following Philippi's (1893) description, it was mentioned by Reiche (1898) in synonymy with $C$. grandiflora. Disuse of the name $C$. laxiflora, during the ensuing century owes mainly to Reiche's (1898) broad circumscription of $C$. grandiflora (Hershkovitz, 2018a; cf. Muñoz Pizarro, 1966). Muñoz Pizarro (1966; see URL in Literature Cited) illustrated a specimen of $C$. laxiflora, but identified it as Calandrinia crassiflora Phil., evidently believing the former to be the same as the latter. The two species are distinct (Hershkovitz, 2018a). Cistanthe laxiflora is not listed in Marticorena and Quezada (1985), which recognized four C. grandiflora segregates in Chile, or Hoffman (1998) for central Chile. Likewise, Marticorena et al. (2001) recognized only C. grandiflora for the Coquimbo Region [and, contra Marticorena and Quezada (1985), did not recognize C. discolor].

As far as I am aware, following Philippi (1893), C. laxiflora was not recognized again until Peralta (1993). Possibly it was not mentioned otherwise since Reiche (1898). Hershkovitz' (2000) molecular phylogenetic analysis included a sample identified by Donna Ford (WVA) as C. laxiflora. Hershkovitz (2006) applied the name "Cistanthe sp., cf. Calandrinia laxiflora Phil." to additional samples. But the combination in Cistanthe was not validated until Zuloaga et al. (2007). Otherwise, application of the name Cistanthe laxiflora has become more common, if not standard, in reference to plants of this taxon: Leubert and Muñoz Schick (2005), O'Quinn et al. (2005), Hershkovitz (2006), Villagrán et al. (2007), Peralta and Ford-Werntz (2008), Ogburn and Edwards (2013), Eyzaguirre Philippi (2016), Rodríguez et al. (2018), and RBGE (2019). As noted, Peralta and Ford-Werntz (2008) and Rodríguez et al. (2018) erroneously listed $C$. speciosa Lehm. and $C$. spectabilis as synonyms of $C$. grandiflora.

At the same time, unlike $C$. speciosa Lehm and C. spectabilis, the name $C$. laxiflora does not seem to have been misapplied or otherwise confused. Reiche (1898) referred C. laxiflora to his Calandrinia grandiflora s.str. form, differing in having especially long peduncles. But, in the sense that Reiche (1898) formally included all Cistanthe set. Cistanthe species in $C$. grandiflora, the name $C$. laxiflora was not misapplied or confused.

Pending additional research and/or formal nomenclatural proposals and pronouncements, the names $C$. speciosa Lehm. and $C$. spectabilis persist as taxonomic albatross. But current taxonomy of Cistanthe sect. Cistanthe and any likely revision thereof mandates that these names be accommodated one way or another. The current classification as synonyms of $C$. grandiflora (Peralta and Ford-Werntz, 2008; Rodríguez et al., 2018) is unsatisfactory, because it is taxonomically incorrect. Listing the names as synonyms of $C$. laxiflora is unacceptable because of priority. Listing them forever as questioned synonyms is legitimate. But the longer definitive resolution is postponed, the more pervasive will become use of $C$. laxiflora, rendering likely an eventual conservation/rejection proposal. Conservation of $C$. speciosa Lehm. or $C$. spectabilis seems to require contriving one or the other or both to be the same as $C$. laxiflora, for no other apparent reason than to conserve the priority of confused and obsolete names over a 
Hershkovitz - Cistanthe

taxonomically clear and current one. It seems more rational to conserve $C$. laxiflora or, perhaps, simply definitively reject $C$. speciosa Lehm. and $C$. spectabilis.

\section{Acknowledgements}

Elaboration of the present paper would not have been possible except for the generous support and dedicated efforts of Katia Chechelnitzky, Sandra Steuermann, and Gabriela Feldman of Fundación Reshet in Chile (www.reshet.cl). Bruce Baldwin (UC/JEPS) and Matthias Schultz (HBG) provided critical bibliographic materials. I also am grateful to Preprints.org for offering this outstanding and effective publication vehicle, and especially to Mila Marinkovic in lovely Belgrade for rapid and excellent attention in the processing of my submissions.

\section{Literature Cited}

Barnéoud, F. N. 1846 [1847]. Portulaceas. In: C. Gay, ed. Historia Fisica y Politica de Chile, Volume 2. Fain \& Thunot, vol. 3. Paris and Museo de Historia Natural de Santiago, Santiago, Chile. https://www.biodiversitylibrary.org/item/152012

Chamisso, A. 1831. De plantis in expeditione Romanzoffianaobservatis disserere pergitur: Arcticae, quae supersunt. Linnaea 6: 545-583. https://www.biodiversitylibrary.org/item/10850

Delprete, P. G., Forneris, G., Pistarino, A. 2002. Carlo Bertero (1789-1831) in the New World. SIDA 20: 621-644. http://www.jstor.org/stable/41968082

Eyzaguirre Philippi, M. T. 2016. Flora de Quinqueles. Fundación R. A. Philippi, Vitacura, Región Metropolitana, Chile. http://fundacionphilippi.cl/sites/default/files/articulos/flora_de_quinqueles_0.pdf

Ford[-Werntz], D. I. 1992. Systematics and Evolution of Montiopsis subgenus Montiopsis (Portulacaceae). PhD dissertation, Washington University, St Louis, MO, USA.

Hershkovitz, M. A. 1991. Taxonomic notes on Cistanthe, Calandrinia, and Talinum. Phytologia 70: 209225. https://www.biodiversity.org/page/12983019

Hershkovitz, M. A. 2006. Evolution of western American Portulacaceae in the Andean region. Gayana 63: 13-74. http://dx.doi.org/10.4067/S0717-66432006000100002

Hershkovitz, M. [A.] 2018a. Synopsis of a new taxonomic synthesis of Montiaceae (Portulacineae) based on rational metadata analysis, with critical new insights on historically poorly understood taxa and a reevaluation of historical biogeography. Preprints 2018080496. https://doi.org/10.20944/preprints201808.0496.v2

Hershkovitz, M. [A.] 2018b. Cistanthe philhershkovitziana (Montiaceae): a remarkable annual species of Cistanthe sect. Cistanthe from Chile. Phytologia 100: 208-221. https://www.phytologia.org/uploads/2/3/4/2/23422706/100_4_208221herhershkovitzcistanthefig3 rev11-1-18.pdf

Hershkovitz, M. [A.] 2018c. Additional notes on Cistanthe philhershkovitziana. Preprints 2018120343. https://doi.org/10.20944/preprints201812.0343.v1

Hershkovitz, M. [A.] 2019. Systematics, Evolution, and Phylogeography of Montiaceae (Portulacineae). Preprints 201903. https://doi.org/10.20944/preprints201903.0206.v2

Hershkovitz, M. A. and E. A. Zimmer. 2000. Ribosomal DNA evidence and disjunctions of western American Portulacaceae. Mol. Phylogen. Evol. 15: 419-439. https://doi.org/10.1006/mpev.1999.0720

Hoffman, A. 1998. Flora Sylvestre de Chile, Zona Central, ed. 6. Fundación Claudio Gay, Santiago, Chile.

Hooker, W. J. 1835. Calandrinia speciosa, showy-flowered calandrinia. Curtis's Bot. Mag. 62 [new series, vol. 9]: 3379. https://www.biodiversitylibrary.org/item/14341 
Hershkovitz - Cistanthe

International Plant Names Index. 2012. www.ipni.org Accessed February 2019.

Lehmann, J. G. C. 1831. Delectus seminum quae in horto Hamburgensium botanico. J. A. Meissneri, Hamburg.

Leubert, F. and M. Muñoz Schick. 2005. Contribución al conocimiento de la flora de las dunas de Concón. Bol. Mus. Nac. Hist. Nat. (Chile): 54: 11-35. http://www2.biologie.fuberlin.de/sysbot/luebert/publ/2005 Luebert Mu\%C3\%B1oz-Schick BolMusNat Concon.pdf

Lilja, N. 1841. Observationes nonnullae botanicae circa nova quaedam genera. Linnaea 15: 259-265. https://www.biodiversity.org/item/10859

Lindley, J. 1833. Calandrinia speciosa, shewy calandrinia. Edwards’s Bot. Reg. 19: 1598. https://www.biodiversitylibrary.org/item/9055

Marticorena, C. and M. Quezada. 1985. Catálogo de la flora vascular de Chile. Gayana (Botánica) 42: 1152.

Marticorena C., F. A. Squeo, G. Arancio, and M. Muñoz [Schick]. 2001. Catálogo de la flora vascular de la IV Región de Coquimbo. In: F. A. Squeo, G. Arancio, and J. R. Gutiérrez, eds. Libro Rojo de la Flora Nativa y de los Sitios Prioritarios para su Conservación: Región de Coquimbo. Univ. La Serena, La Serena, Chile.

Meyen, F. J. F. 1834. Reise um die erde ausgeführt auf dem Königlich preussischen seehandlungs-schiffe Prinzess Louise, commandirt von captain W. Wendt, in den jahren 1830, 1831 und 1832. Sander'sche, Berlin. https://www.biodiversitylibrary.org/item/50795

Muñoz Pizarro, C. 1966. Flores Sylvestres de Chile. Univ. de Chile, Santiago, Chile. [Illustrations of Cistanthe laxiflora (as "Calandrinia crassifolia") and C. discolor: http://www.chlorischile.cl/desiertomunioz/calandrinia.htm]

Muñoz Schick, M. 1985. Flores del Norte Chico, ed. 2. Dirección de Bibliotecas, Archivos y Museos, Ilustr. Mun. La Serena, La Serena, Chile.

Ogburn, R. M. and E. J. Edwards. 2013. Repeated origin of three-dimensional leaf venation releases constraints on the evolution of succulence in plants. Curr. Biol. 23: 722-726. https://doi.org/10.1016/j.cub.2013.03.029

O'Quinn, R., L. Hufford, and A. W. Meerow. 2005. Molecular systematics of Montieae (Portulacaceae): implications for taxonomy, biogeography and ecology. Syst. Bot. 30: 314-331. https://doi.org/10.1600/0363644054223594

Otto, F. and A. Dietrich. 1833. Cultur y Beischreibung der Calandrinia spectabilis, Nob. einer neuen Zier[p]flanze aus Chili, Familie der Portulaceae. Allg. Gartenz. 1: 161-162. https://www.biodiversitylibrary.org/item/50795

Peralta, I. E. 1993. Distribución del género Cistanthe Spach (Portulacaceae) en Sudamérica. Parodiana 8: 153-158.

Peralta, I. E. and D. I. Ford-Werntz. 2008. Portulacaceae. In: F. O. Zuloaga, O. Morrone, M. J. Belgrano, C. Marticorena, and E. Marchesi, eds. Catálogo de las Plantas Vasculares del Cono Sur (Argentina, Sur de Brasil, Chile, Paraguay y Uruguay), vol. 3, Dicotyledoneae: Fabaceae (SennaZygia) - Zygophyllaceae. Missouri Botanical Garden, St. Louis, MO. [Monogr. Syst. Bot. Missouri Bot. Gard. 107: 2796-2817.]

Philippi, R. A. 1860. Viaje al Desierto de Atacama. Eduardo Anton, Halle, Saxony (Germany).

Philippi, R. A. 1893. Plantas nuevas chilenas de las familias rosáceas, onagrariáceas i demás familias del tomo II de Gay: (continuación). Anales Univ. Chile 85: 167-195. https://doi.org/10.5354/0717$\underline{8883.2012 .20472}$

Reiche, C. 1898. Estudios críticos sobre la flora de Chile. Anales Univ. Chile 100: 327-371. [Reiche, C. 1898. Portulacaceae. In: C. Reiche, ed. Flora de Chile, vol. 2. Cervantes, Santiago, Chile.] https://www.biodiversity.org/item/27136

Reiche, K. 1907. Grundzüge der Pflanzenverbreitung in Chile. V. Engelmann, Leipzig.

Reiche, K. 2007. Geografía Botánica de Chile. [Edited republication of G. Looser's 1934 Spanish translation of Reiche, 2007.] Cámara Chilena de la Construcción, Pontificia Universidad Católica de Chile, and Dirección de Bibliotecas, Archivos y Museos, Santiago, Chile.] 
Hershkovitz - Cistanthe

RBGE. 2019. The endemic plants of Chile — an annotated checklist. Royal Botanic Gardens, Edinburgh, UK. https://chileanendemics.rbge.org.uk/taxa/cistanthe-laxiflora-phil-peralta-d-i-ford Accessed 5 April 2019.

Rodríguez, R. C.Marticorena, D. Alarcón, C. Baeza, L. Cavieres, V. L. Finot, N. Fuentes, A. Kiessling, M. Mihoc, A. Pauchard, E. Ruiz, P. Sanchez, and A. Marticorena. 2018. Catálogo de las plantas vasculares de Chile. Gayana 75: 1-430. https://scielo.conicyt.cl/pdf/gbot/v75n1/0717-6643-gbot75-01-1.pdf

Schlechtendal, D. F. L. 1831. Litteratur-Bericht zur Linnaea das Jaar 1831. Linnaea 6 Suppl: 1-158. https://www.biodiversitylibrary.org/item/10850

Spach, E. 1836. Histoire Naturelle des Vegetaux: Phanerogames, vol. 5. Roret, Paris. https://www.biodiversitylibrary.org/item/97959

Squeo, F. A., M. T. K Arroyo, A. Marticorena, G. Arancio, M. Muñoz Schick, M. Negritto, G. Rojas, M. Rosas, R. Rodríguez, A. M. Humaña, E. Barrera, and C. Marticorena. 2008. Catálogo de la flora vascular de la Región de Atacama. In: F. A. Squeo, G. Arancio, and J. R. Guitérrez, eds. Libro Rojo de la Flora Nativa y de los Sitios Prioritarios para su Conservación: Región de Atacama. Univ. La Serena, La Serena, Chile.

Steudel, E. T. 1840. Nomenclator botanicus, seu, Synonymia plantarum universalis: enumerans ordine alphabetico nomina atque synonyma, tum generica tum specifica, et a Linnaeo et a recentioribus de re botanica scriptoribus plantis phanerogamis imposita. J. G Cottae, Tubingen. https://www.biodiversity.org/item/11567

Veldkamp, J. F. 2015. (2346) Proposal to conserve the name Calandrinia grandiflora (Cistanthe grandiflora) against Calandrinia glauca (Montiaceae). Taxon 64: 174-175. https://doi.org/10.12705/641.12

Villagrán, C., C. Marticorena, and J. J. Armesto. 2007. Flora de las plantas vasculares de Zapallar. Puntángeles y Fondo Editorial U.M.C.E., Santiago, Chile.

Zuloaga, O., O. Morrone, and M. J. Belgrano. 2007. Novedades taxonómicas y nomenclaturales para la flora vascular del cono sur de Sudamérica. Darwiniana 45: 236-241. http://www.scielo.org.ar/pdf/darwin/v45n2/v45n2a11.pdf 